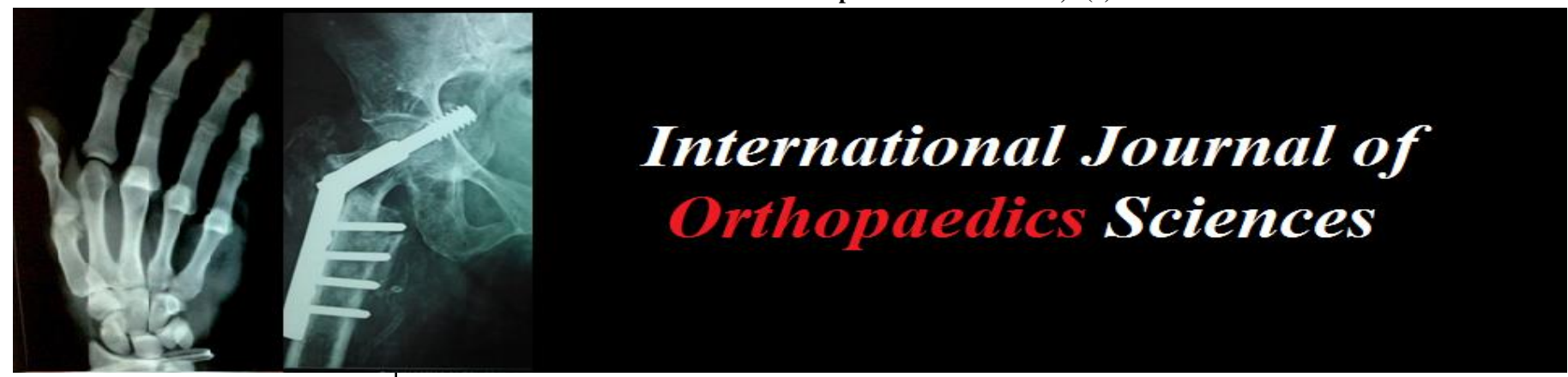

ISSN: $2395-1958$

IJOS 2019; 5(1): 472-476

(C) 2019 IJOS

www.orthopaper.com

Received: 02-11-2018

Accepted: 05-12-2018

Dr. Sravya Teja Paleti

MS Ortho, Assistant professor in Orthopaedics, Dept of

Orthopaedics ASRAM Medical

College, Eluru, West Godavari,

Andhra Pradesh, India

Dr. R Naresh Kumar

MS Ortho, Consultant

Orthopaedic Surgeon

Vijayawada, Andhra Pradesh,

India

\section{Assessing the functional and Radiological outcome in surgically treated closed tibial plateau fractures in adults: A case series of $\mathbf{4 0}$ cases}

\section{Dr. Sravya Teja Paleti and Dr. R Naresh Kumar}

DOI: $\underline{\text { https://doi.org/10.22271/ortho.2019.v5.i1i.82 }}$

Abstract

Introduction: Knee being one of the major weight bearing joints of the body, fractures around it will be of paramount importance. This study is to analyze the functional outcome of CRIF or ORIF with or without bone grafting in tibial plateau fractures in adults.

Materials and Methods: 40 cases of tibial plateau fractures treated by various modalities were studied from 1-8-2013 to 31-8-2015 and followed for a minimum of 6 months. Fractures were evaluated using Modified Rasmussen's Clinical, Radiological grading system.

Results: The selected patients were evaluated thoroughly and after the relevant investigations, were taken for surgery. The fractures were classified as per the SCHATZKER'S types and operated accordingly with CRIF with Percutaneous cannulated cancellous screws, ORIF with buttress plate/LCP with or without bone grafting.

Immobilization of fractures continued for 3 weeks by POP slab. Early range of motion was then started. Weight bearing up to 6- 8 weeks was not allowed. The full weight bearing deferred until 12 weeks or complete fracture union. The knee range of motion was excellent to very good, gait and weight bearing after complete union was satisfactory, knee stiffness in 3 cases, wound dehiscence and infection in 1 case and non-union in none of our cases was noted.

Conclusion: Functional outcome is better in operatively treated tibial plateau fractures in adults, because it gives excellent anatomical reduction and rigid fixation to restore articular congruity and early motion thereby preventing knee stiffness.

Keywords: Tibial plateau fractures, schatzker classification, open reduction, internal fixation, closed reduction, modified Rasmussen criteria

\section{Introduction}

Tibial plateau fractures are one of the commonest intra-articular fractures. This makes about $1 \%$ of all fractures and $8 \%$ of the fractures in elderly. Most injuries affect lateral tibial condyle (55 to $70 \%$ ) and isolated medial condyle fractures occur in 10 to $23 \%$ whereas the involvement of bicondylar lesions is found in 10 to $30 \%$ of the reported series ${ }^{[1]}$.

We have advanced from the conservative approach to internal fixation in fractures as an acceptable mode of treatment. Nevertheless, tibial plateau fractures remain challenging because of their number, variety and complexity. Despite a plethora of articles, written in the past 50 years that have addressed the problems of classification and results of various treatments, the optimal method of management remains controversial ${ }^{[2]}$.

\section{Aims \& Objectives}

1. To evaluate the Functional outcome in tibial plateau fractures treated with CRIF, ORIF.

2. To assess and compare Functional vs Radiological outcomes after surgery.

\section{Materials and Methods}

During this study 40 patients were treated for tibial plateau fractures in which all patients were treated by internal fixation, out of which, 14 with Percutaneous cancellous screw fixation method, 10 with ORIF with buttress plate, 13 with ORIF with buttress plate and bone grafting and 3 with Locking compression plate.
Dr. Sravya Teja Paleti

MS Ortho, Assistant Professor in Orthopaedics, Dept of

Orthopaedics ASRAM medica

College, Eluru, West Godavari,

Andhra Pradesh, India 


\section{The inclusion criteria}

1. Patient who has been diagnosed as Closed, Unstable tibial plateau fracture

2. Age group of $35-70$ years of both sexes.

\section{The exclusion criteria}

1. Skeletally immature individuals.

2. Open fractures of tibial plateau.

3. Fractures associated with knee dislocation.

4. Patients with associated ipsilateral femur, tibia and foot fractures.

- All patients are selected on the basis of history, clinical examination and radiography.

- The Schatzker's classification was used to classify these fractures. The patients were followed up for an average period of 6 months.

Fractures will be defined as unstable if any of the following are present:

Depression $>4 \mathrm{~mm}$

Displacement $>10 \mathrm{~mm}$

Instability $>10^{\circ}$

- All cases will be treated with open reduction and internal fixation.

- Fixation can be done by Cannulated cancellous screw fixation, AO type $\mathrm{T}$ or L-plate, Locking Compression Plate.

- Follow up and assessment will be performed using modified Rasmussen's Clinical and Radiological criteria.

\section{Management}

The patients were first seen in the casualty. Concerned specialists undertook appropriate management of the associated injuries. Intensive care was given to those patients who presented with shock and immediate resuscitative measures were taken. Once the patient's general condition was fit, relevant X-rays were taken and the degree of instability graded. The patients were taken for surgery at the earliest possible time depending on their medical condition, skin condition and the amount of swelling. All surgeries were done under $\mathrm{C}$-arm image intensifier control. Fractures were fixed either with percutaneous technique or by open reduction and internal fixation. The fixation devices consisted of $\mathrm{T}$ Buttress plate, L Buttress plates, $4.5 \mathrm{~mm}$ Cortical screws and $6.5 \mathrm{~mm}$ Cannulated and Non-cannulated Cancellous screws.

Bone grafts, Bone graft substitutes were used in depressed and comminuted fractures. The source of bone graft was ipsilateral iliac crest.

\section{Postoperative protocol}

Postoperatively patients were immobilized with an above knee posterior slab or a compression bandage for 3 weeks. The sutures were removed on the $12^{\text {th }}$ postoperative day. Antibiotics were given till suture removal by 5 days of intravenous and 7 days of oral. The patients were advised static quadriceps exercises for initial 3 weeks followed by passive range of motion with protected knee brace and nonweight bearing crutch walking up to 6 weeks. After 6 weeks knee mobilization and weight bearing crutch walking was advocated. An immediate postoperative X-ray was also done, later on repeated at 6 weeks, 3 months and 6 months.

\section{Follow up protocol}

The First follow up was done at 2 weeks, during which the surgical scar was inspected and range of movements noted.

The Second follow up done at 6 weeks during which an X-ray was taken to look for signs of fracture union and loss of reduction if any.

The Third follow up was done at 3 months during which one more X-ray was done and a clinical evaluation of union done. Based on the clinical and radiological signs of union patients were allowed partial weight bearing and gradually progressed to full weight bearing.

The patients were then followed up at 6 months, during which time the anatomic and functional evaluation was done using the modified Rasmussen clinical and radiological criteria.

\section{Instruments used in proximal tibial fractures}

The various instruments required are -

1. Reduction clamps (pointed) for reducing the fracture site

2. Periosteum elevator for elevation of periosteum

3. Screw drivers for $4.5 \mathrm{~mm}$ cortical screws, $4 \mathrm{~mm}$ and $6.5 \mathrm{~mm}$ cancellous screws

4. Hand drill, Power drill

5. Drill bit of $3.2 \mathrm{~mm}$ for drilling the bone

6. Tap of different sizes ie., $4.5 \mathrm{~mm}$ and $6.5 \mathrm{~mm}$ tap.

7. Depth guage for measuring the appropriate size of screws.

8. Bone grafting set (mallet, osteotomes)

9. Bone impaction set

\section{Implants used in proximal tibial fractures}

1. $6.5 \mathrm{~mm}$ Cancellous bone screw with $8 \mathrm{~mm}$ spherical head and $3.5 \mathrm{~mm}$ hexagonal recess, thread length $16 \mathrm{~mm}$, with $4.5 \mathrm{~mm}$ shaft, $3 \mathrm{~mm}$ core, $3.2 \mathrm{~mm}$ drill bit and $6.5 \mathrm{~mm}$ tap.

2. $4 \mathrm{~mm}$ Cancellous bone screw, with $6 \mathrm{~mm}$ head, $2.5 \mathrm{~mm}$ hexagonal recess, core diameter $1.9 \mathrm{~mm}, 1.7 \mathrm{~mm}$ pitch, $2.5 \mathrm{~mm}$ drill bit and $4 \mathrm{~mm}$ tap.

3. $4.5 \mathrm{~mm}$ Cortical bone screw, with $4.5 \mathrm{~mm}$ shaft, $3 \mathrm{~mm}$ core, $3.2 \mathrm{~mm}$ drill bit and $4.5 \mathrm{~mm}$ tap.

4. K- wires

\section{Buttress Plates}

T Buttress plate

$\mathrm{L}$ buttress plate with right and left offset.

Locking Compression Plates: with Locking screws $4.5 \mathrm{~mm}$ for Proximal Tibia. 

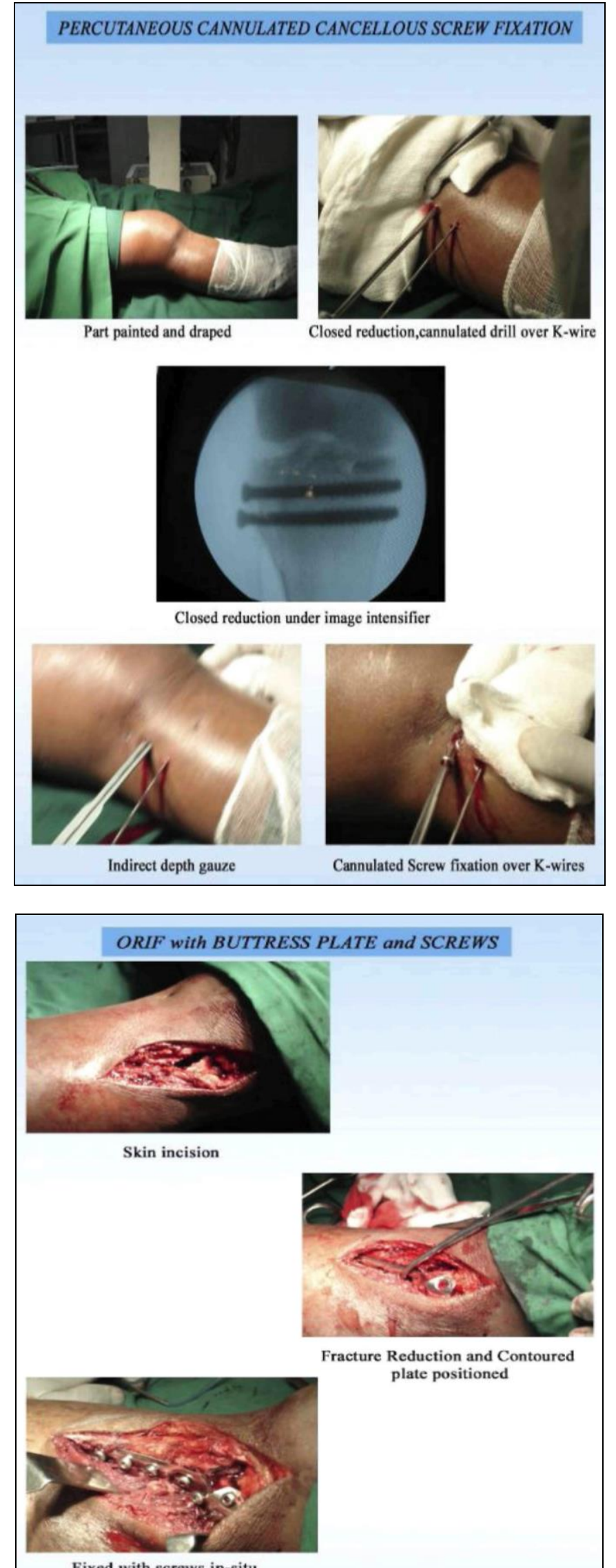

Fixed with screws in-situ

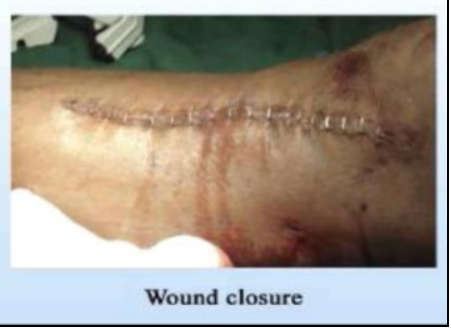

Sex incidence

Highly significant association of this study with male patients.

Table 1: Frequency of Sex incidence

\begin{tabular}{|c|c|c|}
\hline Sex Of The Patient & No Of Patients & Percentage \\
\hline Male & 28 & $70 \%$ \\
\hline Female & 12 & $30 \%$ \\
\hline Total & 40 & $100 \%$ \\
\hline
\end{tabular}

\section{AGE Incidence}

Highly significant association fracture in the $3^{\text {rd }}$ and $4^{\text {th }}$ decades.

Table 2: Frequency of Age incidence

\begin{tabular}{|c|c|c|}
\hline Age of the patient & Frequency & Percentage \\
\hline$<35$ & 6 & $15 \%$ \\
\hline $35-45$ & 9 & $22.5 \%$ \\
\hline $45-55$ & 14 & $35 \%$ \\
\hline $55-70$ & 11 & $27.5 \%$ \\
\hline Total & 40 & $100 \%$ \\
\hline
\end{tabular}

\section{Mode of Injury}

In this study mode of injury is highly associated with road traffic accident which accounts for about $60 \%$.

\section{Side of Injury}

In our study, there was left sided predominance, compared to the right side.

\section{Type of fracture}

\section{Schatzker's classification}

In our study, the majority of the fractures were found to be of type II fracture types i.e. Cleavage combined with Depression fractures.

Table 3: Frequency of Type of Fracture

\begin{tabular}{|c|c|c|}
\hline Schatzker type of fracture & No. of cases & Percentage \\
\hline TYPE I & 7 & $17.5 \%$ \\
\hline TYPE II & 10 & $25 \%$ \\
\hline TYPE III & 8 & $20 \%$ \\
\hline TYPE IV & 4 & $10 \%$ \\
\hline TYPE V & 4 & $10 \%$ \\
\hline TYPE VI & 7 & $17.5 \%$ \\
\hline Total & 40 & $100 \%$ \\
\hline \multicolumn{2}{|l}{}
\end{tabular}

\section{Methods of treatment}

14 cases were managed with Percutaneous cannulated screws, 10 were managed with Buttress plate, 13 by Buttress plate along with Bone graft and 3 cases with Locking plate.

Table 4: Frequency of methods of treatment

\begin{tabular}{|c|c|c|}
\hline Methods of treatment & No. of cases & Percentage \\
\hline PCCS & 14 & $35 \%$ \\
\hline ORIF with BP & 10 & $25 \%$ \\
\hline ORIF with BP + BG & 13 & $32.5 \%$ \\
\hline ORIF with LCP & 3 & $7.5 \%$ \\
\hline Total & 40 & $100 \%$ \\
\hline
\end{tabular}

Pccs - Per Cutaneous Cannulated Cancellous Screw

Orif - Open Reduction Internal Fixation

Bp- Buttress Plate

Bg-Bone Graft

Lcp - Locking Compression Plate 


\section{Complications}

All fractures united within expected time, not a single nonunion was noted in our series. The cases with wound infection also had stiffness of the knee joint

Table 5: Frequency of Complications

\begin{tabular}{|c|c|c|}
\hline Complication & $\begin{array}{c}\text { No. Of } \\
\text { Cases }\end{array}$ & Percentage \\
\hline Knee Stiffness & 5 & $12.5 \%$ \\
\hline Varus/Valgus Deformity & 1 & $2.5 \%$ \\
\hline Infection, Wound Dehiscence & 3 & $7.5 \%$ \\
\hline Normal & 31 & $77.5 \%$ \\
\hline Total & 40 & $100 \%$ \\
\hline
\end{tabular}

\section{Associated ligamentous injuries}

MCL injury was the most commonly associated ligament injury in our series followed by ACL, LCL.

All the ligamentous injuries were managed conservatively by a Brace. The patient's function and outcome were good even without addressing these injuries.

\section{Grading Criteria}

Table 6: Modified Rasmussen criteria for clinical assessment

\begin{tabular}{|c|c|}
\hline $\begin{array}{l}\text { Pain } \\
\text { None }\end{array}$ & 6 \\
\hline Occasional & 5 \\
\hline Stabbing pain in certain position & 3 \\
\hline Constant pain after activity & 1 \\
\hline Significant rest pain & 3 \\
\hline \multicolumn{2}{|l|}{ Walking Capacity } \\
\hline Normal walking capacity for age & 6 \\
\hline Walking outdoor more than one hour & 5 \\
\hline Walking outdoor 15 mins- $1 \mathrm{hr}$ & 3 \\
\hline Walking ourdoor $<15$ mins & 1 \\
\hline Walking indoor only & 0 \\
\hline Wheel chair or bed ridden & 3 \\
\hline \multicolumn{2}{|l|}{ Knee Extension } \\
\hline Normal & 4 \\
\hline Lack of extension $<10^{0}$ & 2 \\
\hline Lack of extension $>10^{0}$ & 0 \\
\hline Lack of extension $>20^{0}$ & 2 \\
\hline \multicolumn{2}{|l|}{ Total Range of Motion } \\
\hline Full & 6 \\
\hline Atleast $120^{\circ}$ & 5 \\
\hline Atleast $90^{0}$ & 3 \\
\hline Atleast $60^{0}$ & 1 \\
\hline$<60^{0}$ & 3 \\
\hline \multicolumn{2}{|l|}{ Stability } \\
\hline Normal stability in Extension and $20^{0}$ Flexion & 6 \\
\hline Abnormal in stability in $20^{\circ}$ Flexion & 4 \\
\hline Instability in Extension $<10^{0}$ & 2 \\
\hline Instability in Extension $>10^{\circ}$ & 0 \\
\hline \multicolumn{2}{|l|}{ Power of quadriceps } \\
\hline Grade 5 & 2 \\
\hline Grade 3-4 & 1 \\
\hline Grade $<3$ & 2 \\
\hline Maximum score & 30 \\
\hline Excellent & $28-30$ \\
\hline Good & $24-27$ \\
\hline Fair & $20-23$ \\
\hline Poor & $<20$ \\
\hline
\end{tabular}

Table 7: Modified Rasmussen criteria for radiological assessment

\begin{tabular}{|c|c|}
\hline Articular depressions & \\
\hline None & 3 \\
\hline$<5 \mathrm{~mm}$ & 2 \\
\hline $6-10 \mathrm{~mm}$ & 1 \\
\hline$>10 \mathrm{~mm}$ & 0 \\
\hline \multicolumn{2}{|l|}{ Condylar widening } \\
\hline None & 3 \\
\hline$<5 \mathrm{~mm}$ & 2 \\
\hline $6-10 \mathrm{~mm}$ & 1 \\
\hline$>10 \mathrm{~mm}$ & 0 \\
\hline \multicolumn{2}{|l|}{ Valgus / Varus angulation } \\
\hline None & 3 \\
\hline$<10^{0}$ & 2 \\
\hline $10^{0}-20^{0}$ & 1 \\
\hline$>20^{0}$ & 0 \\
\hline \multicolumn{2}{|l|}{ Osteoarthrosis } \\
\hline None / No progress & 1 \\
\hline Progression by 1 grade & 0 \\
\hline Progression by $>1$ grade & 1 \\
\hline Maximum score & 10 \\
\hline Excellent & $9-10$ \\
\hline Good & $7-8$ \\
\hline Fair & $5-6$ \\
\hline Poor & $<5$ \\
\hline
\end{tabular}

\section{Clinical Evaluation}

The mean Rasmussen Functional score at final follow up was 25.062 (range 15-30).

Table 8: Clinical Assessment

\begin{tabular}{|c|c|c|}
\hline Clinical Result & No. Of Cases & Percentage \\
\hline Excellent & 19 & $47.5 \%$ \\
\hline Good & 16 & $40 \%$ \\
\hline Fair & 3 & $7.5 \%$ \\
\hline Poor & 2 & $5 \%$ \\
\hline Total & 40 & $100 \%$ \\
\hline
\end{tabular}

\section{Radiological Evaluation}

The mean Rasmussen Radiological score at final followup was 7.68 (range 0-9).

Table 9: Radiological Assessment

\begin{tabular}{|c|c|c|}
\hline Radiological Evaluation & No. Of Cases & Percentage \\
\hline Excellent & 5 & $12.5 \%$ \\
\hline Good & 27 & $67.5 \%$ \\
\hline Fair & 5 & $12.5 \%$ \\
\hline Poor & 3 & $7.5 \%$ \\
\hline Total & 40 & $100 \%$ \\
\hline
\end{tabular}

Table 10: Rasmussen's grading

\begin{tabular}{|c|c|c|c|c|}
\hline Criteria & Excellent & Good & Fair & Poor \\
\hline Pain evaluation & 18 & 13 & 9 & 0 \\
\hline Walking capacity & 18 & 14 & 6 & 2 \\
\hline Extension lag & 19 & 14 & 5 & 2 \\
\hline Range of movement & 21 & 10 & 5 & 4 \\
\hline Stability & 25 & 15 & 0 & 0 \\
\hline Functional Results & 19 & 16 & 3 & 2 \\
\hline Radiological Results & 5 & 27 & 5 & 3 \\
\hline
\end{tabular}

- It was also noted that Clinical results had no significant association with follow up Radiographs (Chi square test, $\mathrm{p}$ value $=0.176$ ) 


\section{Discussion}

Aim of study is to assess functional outcome and radiological outcome in operatively treated tibial plateau fractures in 40 cases. The analysis of the results were made in terms of - age of the patient, sex distribution, mode of injury, side of fracture, analysis of the types, modalities of treatment, complications, associated injuries and the functional outcome. In this series we studied 40 cases of tibial plateau fractures treated only by surgical methods. Different authors use different criteria for the surgical management of these fractures. Seppo E, Honkonen conducted 130 tibial plateau fractures taking into consideration the following for the surgical management: -

Condylar widening of $>5 \mathrm{~mm}$

Lateral condyle step off $>3 \mathrm{~mm}$

All medial condylar fractures

In our study, the indications for the surgery were the same standard indications as above and $3 \mathrm{~mm}$ depression was considered as an indication for surgery in our series ${ }^{[3]}$.

In our series we have not formulated any criteria as to particular method of fixation for particular type of fracture. So each case was individualized and treated accordingly as it needed. Most of the type I, some type II were treated with Percutaneous cancellous screw fixation. The split fracture, of $>3 \mathrm{~mm}$ displacement was treated by ORIF. Bone grafting was included along with ORIF with Buttress plate/LCP and screws in type II, III, IV, V and VI wherever necessary.

The major problem faced by us during the study was Knee stiffness and Infection, hence immobilization was more in these patients for stiffness. The infection might be attributed to nosocomial infection.

Inspite of all the associated Ligament injuries and Complications, we were able to achieve $47.5 \%$ excellent result, $40 \%$ good result (Overall $87.5 \%$ acceptable results). In addition we have $7.5 \%$ fair and $5 \%$ poor results. These results are comparable and on par with other documented standard studies.

These results are comparable and on par with other documented standard studies.

\begin{tabular}{|c|c|}
\hline Study & Satisfactory Results \\
\hline Rambold, 1992 & $93 \%$ \\
\hline Seppo E, 1993 & $86 \%$ \\
\hline Joseph Schatzker, 1986 & $86 \%$ \\
\hline Our Study, 2018 & $87.5 \%$ \\
\hline
\end{tabular}

\section{Conclusion}

\section{The conclusions of these studies are}

1. Displaced condylar fractures of tibial plateau those belonging to Schatzker' stype I and II, the treatment of choice is closed reduction internal fixation/Open reduction internal fixation with Cannulated Cancellous screws. Results are excellent to good by this method.

2. The main aim of surgical treatment include accurate reconstruction of the articular surface with elevation of the depressed bone fragment, bone grafting, stable fragment fixation allowing early range of movement.

3. Schatzker's type III managed operatively with ORIF with Buttress plate and bone grafting gives good to fair results.

4. In Schatzker's type IV fractures which were managed by ORIF and Buttress plating had fair to good results.

5. In high velocity injuries belonging to Schatzker V and VI which were managed with Buttress plate/LCP, number of good to fair results were seen.
Functional outcome is better in operatively treated tibial plateau fractures in adults, because it gives excellent anatomical reduction and rigid fixation to restore articular congruity and early motion thereby preventing knee stiffness.

\section{References}

1. Marsh JL, Tibial Plateau Fractures, chapter 53 in Rockwood and Green's fractures in adults, Bucholz RW.

2. Susan Standring. Knee in Gray's Anatomy. Newell R LM and Davies. MS 29th Ed. Spain Elsevier Churchill Livingstone. 2005, 1471-86.

3. Moore TM, Harvey JP. Roentgenographic measurement of tibial plateau depression due to fractures. J Bone \& Joint Surg 1974; 56(Am): 155.

4. Roberts JM. Fractures of the condyles of tibia, An anatomical and clinical end result study of 100cases. J Bone \& Joint Surg. 1968; 50(Am):1505. 